

\section{ESTRUTURAÇÃO DOS PROCESSOS DE GESTÃO DE PORTFÓLIO DE PROJETOS: UMA PROPOSTA NO CENTRO DE ESTUDOS AVANÇADOS EM SEGURANÇA DE BARRAGENS} PROJECT PROTOCOL MANAGEMENT: A SYSTEMATIC BIBLIOGRAPHIC REVIEW

${ }^{1}$ Mestre em Tecnologias, Gestão e Sustentabilidade. Especialista em Gestão Empresarial. Graduada em Secretariado Executivo e Administração de Empresas. Gerente de Projetos.

Membro do Grupo de Pesquisa Inovação em Ambientes de Tecnologia (INOVATEC).

aly.xandra84@gmail.com

2 Engenheiro Químico, Mestre e Doutor em Engenharia Química (Desenvolvimento de Processos Químicos e Bioquímicos), Especialista em gestão estratégica de pesquisa, desenvolvimento e inovação. Professor de Engenharia Mecânica e Coordenador do Programa de Pós-Graduação em Tecnologias, Gestão e Sustentabilidade (PPGTGS).

Líder do Grupo de Pesquisa INOVATEC. Coordenador da Região Sul do Fórum dos Programas Profissionais de Pós-Graduação - FOPROF.

Diretor Presidente do ITAI - Instituto de Tecnologia Aplicada e Inovação.

eduardo.dechechi@unioeste.br

Recebido em: 07 nov. 2019

Aprovado em: 03 out. 2020
Resumo: O gerenciamento de portfólio tem se mostrado cada vez mais necessário nas organizações que utilizam projetos para alcançar suas estratégias e está se tornando uma questão básica de sobrevivência. Entretanto, existe uma lacuna na literatura no que se refere a aplicação das técnicas nas empresas. Este estudo direcionou esforços para elaborar uma proposta de estruturação dos processos de gestão de portfólio de projetos para o Centro de Estudos Avançados em Segurança de Barragens (Ceasb), devido a necessidade de se buscar, a partir da construção e aprimoramento das etapas, a maximização da imparcialidade e a melhora dos processos de maneira a alinhar aos objetivos estratégicos da organização. Para relatar a elaboração utilizou-se como estratégia de pesquisa o método de pesquisaação. O resultado desta proposta subsidiou o Ceasb na melhora de seus processos, métodos e ferramentas de gerenciamento de portfólio. Além disso, vem contribuir com a construção do conhecimento técnico-científico em gestão de portfólio de projetos por meio de uma aplicação prática.

Palavras-chave: Gerenciamento de Portfólio de Projetos. Gestão de projetos. Processos.

Abstract: Portfolio management has been shown to be increasingly necessary in organizations that use projects to achieve their strategies and is becoming a basic issue of survival. However, there is a gap in the literature regarding the application of techniques in companies. This study directed efforts to elaborate a proposal for structuring the project portfolio management processes for the Center for Advanced Studies on Dam Safety (Ceasb), due to the need to seek, from the construction and improvement of the stages, the maximization of impartiality and the improvement of processes in order to align with the strategic objectives of the organization. To report the elaboration, the research-action method was used as a research strategy. The result of this proposal helped Ceasb to improve its portfolio management processes, methods and tools. In addition, it contributes to the construction of technical and scientific knowledge in project portfolio management through practical application.

Keywords: Project Portfolio Management. Project management. Processes. 


\section{Introdução}

A gestão de portfólio pode ser definida como uma série de modelos, procedimentos e processos que visam administrar um conjunto de projetos de forma sistêmica (CARVALHO; RABECHINI JUNIOR, 2008). A seleção de projetos para a constituição de portfólios não é uma área de conhecimento recente e vem sendo estudada há décadas em diversos âmbitos de aplicação, tais como a indústria de novos produtos, a farmacêutica e a de exploração de petróleo (COOPER et al., 2001).

O gerenciamento de portfólio de projetos (Project Portfolio Management - PPM), surge nas últimas décadas da integração entre as áreas de gestão de projetos e gestão de portfólio. O PMI (Project Management Institute) atualizou, em 2008, o seu padrão de Gerência de Portfólio (PMI, 2008) a fim de adequá-lo às necessidades das diversas organizações que o utilizam como guia de boas práticas.

A importância desse tema refere-se à necessidade da empresa em conseguir, com recursos financeiros, humanos e tecnológicos limitados, aproveitar as oportunidades de projetos que the confiram maior vantagem, de acordo com a estratégia competitiva adotada pela organização (ROZENFELD et al., 2006). Essa relevância traduz a preocupação das instituições em optar por projetos mais adequados aos seus objetivos organizacionais.

O processo de gestão de portfólio envolve análise e revisão constante, ou seja, periodicamente os projetos precisam ser analisados quanto a sua evolução, resultados e viabilidade em serem mantidos no portfólio da empresa (COOPER; EDGETT; KLEINSCHMIDT, 1999). A decisão de manter ou não um projeto pode envolver riscos e conflitos organizacionais se não executada de forma estruturada e clara, com a participação efetiva de todos os envolvidos (GHASEMZADEH; ARCHER; IYOGUN, 1999). Neste sentido, as organizações optaram por unir o gerenciamento de portfólio à governança diminuindo os riscos de iniciativas mal alinhadas ou de baixa prioridade consumirem recursos, garantindo assim que a estratégia organizacional possa ser alcançada.

As práticas de gestão de portfólio de projetos decorrem de um processo estruturado de identificação das oportunidades de projetos, avaliação inicial da viabilidade das ideias, avaliação dos potenciais projetos de acordo com os critérios estratégicos estabelecidos, priorização dos projetos, seleção dos projetos, alocação dos recursos, acompanhamento da execução e retroalimentação dos resultados para verificação da aderência ao planejamento estratégico.

A ideia de propor o aprimoramento das etapas do processo de gerenciamento de portfólio de projetos de P\&D para o Centro de Estudos Avançados em Segurança de Barragens - Ceasb, é decorrente do vínculo da pesquisadora com as atividades de gerenciamento de projetos de P\&D. Ademais, a necessidade de se buscar, a partir da construção e aprimoramento das etapas, a maximização da imparcialidade e a melhora dos processos de maneira a alinhar aos objetivos estratégicos da 
organização. No Ceasb, as propostas de projetos de pesquisa de P\&D são recebidas e enviadas ao Comitê Técnico para análise e aprovação.

O objetivo deste relato técnico é descrever como foi realizada a estruturação da proposta de processo de gestão de portfólio de projetos do Centro de Estudos Avançados em Segurança de Barragens (Ceasb). Para isso, este trabalho está estruturado em 5 seções, incluindo a introdução. $\mathrm{Na}$ seção 2, apresenta-se uma breve revisão de literatura sobre os modelos de portfólio de projetos de P\&D. São apresentados os aspectos metodológicos da pesquisa, na seção 3. A intervenção e a apresentação dos resultados são relatadas na seção 4, seguido da seção 5 com as considerações finais.

\section{Referencial teórico}

Archer e Gasemzadeh (1999) definem gerenciamento de portfólio como uma coleção de projetos que são desenvolvidos sob a administração de uma unidade organizacional. Cada projeto pode se relacionar com outros ou ser independente, no entanto, devem fazer parte de objetivos estratégicos da organização.

Para Carvalho e Rabechini (2006), o gerenciamento de portfólio é utilizado quando é preciso administrar um conjunto de projetos, ou seja, no momento em que a expansão da visão gerencial tornase necessária.

Segundo Fernandes e Abreu (2008), a ausência da gestão de portfólio de projetos compromete a comunicação das prioridades da organização, a identificação de riscos e redundâncias e a alocação otimizada de recursos.

O gerenciamento de portfólio de projetos, conforme relatam Dinsmore e Brewin (2009), consiste em um conjunto de processos, com a finalidade de possibilitar análise, recomendação, autorização, agilidade e monitoramento dos projetos para atingir os objetivos organizacionais.

Barcaui (2012) também destaca alguns benefícios do gerenciamento de portfólio: obtenção de meios para selecionar a carteira ideal, gestão de recursos de maneira corporativa, melhoria da visibilidade e gestão dos empreendimentos da organização, obtenção de informações para tomada de decisão, entre outros.

A complexidade que existe no processo de gerenciamento de portfólio faz com que poucas empresas utilizem as ferramentas certas e suas potencialidades (RABECHINI JR., MAXIMIANO E MARTINS, 2005). A utilização do gerenciamento de portfólio acontece quando as empresas que necessitam gerenciar uma grande quantidade de projetos precisam administrar de forma sistemática os seus recursos. A gestão de portfólio é descrita como uma ferramenta organizacional responsável por permitir que as empresas alcancem os objetivos estratégicos. Os processos de gestão do portfólio 
devem facilitar a tomada de decisão e definir os objetivos de investimento da organização (KAISER et al., 2015).

Neste sentido a gestão de portfólio proporciona um alinhamento com a estratégia da organização equilibrando oportunidades ao uso racional dos recursos.

\section{Metodologia}

A estratégia de pesquisa utilizada para este trabalho foi o método de pesquisa-ação, que de acordo com Thiollent (1986, p.14) é um tipo de pesquisa social com base empírica que é concebida e realizada em estreita associação com uma ação ou com a resolução de um problema coletivo no qual o pesquisador se envolve de modo participativo e colaborativo. Ressalta-se a aderência deste método de pesquisa com o trabalho devido a participação dos pesquisadores no desenvolvimento da solução para o problema em questão. Além disso, a pesquisadora atua no Ceasb e é responsável pelo processo de gerenciamento de portfólio do centro.

O trabalho foi estruturado em três etapas: revisão bibliográfica, revisão sistemática de literatura com ênfase em portfólio, a coleta e análise das informações do Ceasb e a elaboração da proposta conceitual de estruturação dos processos de gestão de portfólio de projetos.

Foram realizadas pesquisas bibliográficas, especialmente para o levantamento dos modelos de gerenciamento de portfólio de projetos existentes. Como complemento, também foi realizada uma revisão sistemática acerca do tema em estudo. As buscas foram realizadas nas bases científicas Scopus, Web of Science e Scielo, selecionadas devido sua relevância para a comunidade acadêmica, totalizando 78 artigos, destes após o processo de extração resultou em 11 artigos para leitura completa e análise, compondo assim o portfólio bibliográfico. 
Figura 1

Resumo do protocolo

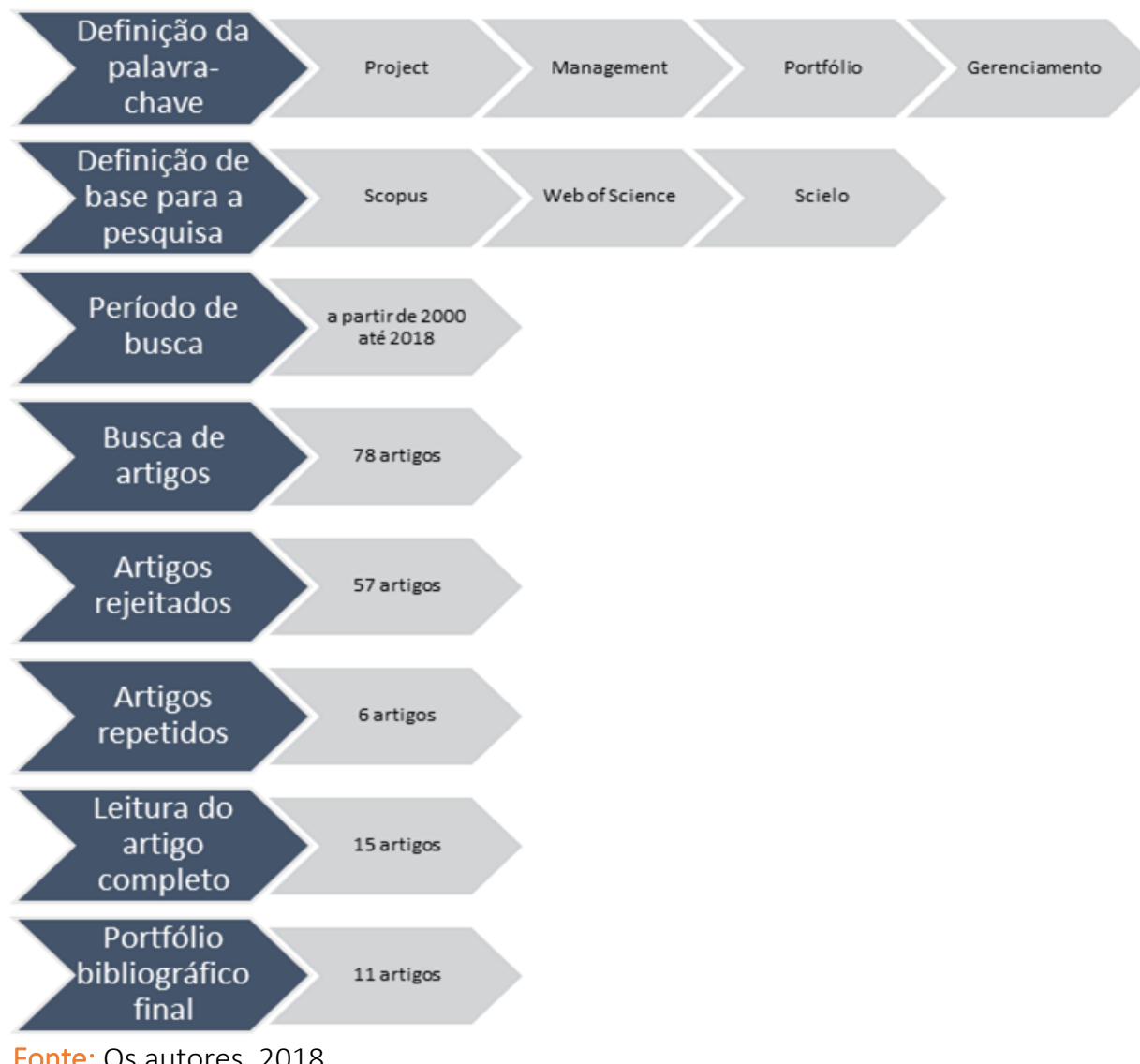

Fonte: Os autores, 2018.

Como complemento da revisão de literatura, foram lidos e analisados 11 artigos, resultantes da revisão sistemática, conforme apresentado na tabela 1 . 
Tabela 1

Resumo das publicações

\begin{tabular}{|c|c|c|c|c|}
\hline & Autores & Artigo & Revista Publicada & Citações \\
\hline 1 & $\begin{array}{c}\text { MORAES, R. O., \& LAURINDO, F. } \\
\text { J. B. (2003). }\end{array}$ & $\begin{array}{l}\text { Um estudo de caso de gestão } \\
\text { de portfólio de projetos de } \\
\text { tecnologia da informação }\end{array}$ & Gestão \& Produção & 46 \\
\hline 2 & $\begin{array}{l}\text { RABECHINI JR., R, MAXIMIANO, } \\
\text { A. C. A, \& MARTINS, V. A. (2005). }\end{array}$ & $\begin{array}{l}\text { A adoção de gerenciamento de } \\
\text { portfólio como uma alternativa } \\
\text { gerencial. O caso de uma } \\
\text { empresa prestadora de serviço } \\
\text { de interconexão eletrônica }\end{array}$ & Revista Produção & 76 \\
\hline 3 & $\begin{array}{c}\text { CASTRO, H. G., \& CARVALHO, M. } \\
\text { M. (2010). }\end{array}$ & $\begin{array}{l}\text { Gerenciamento do portfólio de } \\
\text { projetos: um estudo } \\
\text { exploratório }\end{array}$ & Gestão \& Produção & 70 \\
\hline 4 & $\begin{array}{c}\text { CASTRO, H. G., \& CARVALHO, M. } \\
\text { M. (2010). }\end{array}$ & $\begin{array}{l}\text { Gerenciamento do portfólio de } \\
\text { projetos (ppm): estudos de } \\
\text { caso }\end{array}$ & Production & 33 \\
\hline 5 & $\begin{array}{l}\text { BUYS, A.J., \& STANDER, M.J.. } \\
\text { (2010). }\end{array}$ & $\begin{array}{l}\text { Linking projects to business } \\
\text { strategy through project } \\
\text { portfolio management }\end{array}$ & $\begin{array}{l}\text { South African Journal of } \\
\text { Economic and } \\
\text { Management Sciences }\end{array}$ & 25 \\
\hline 6 & $\begin{array}{l}\text { JAEGER NETO, J. I., LUCIANO, E. } \\
\text { M., \& TESTA, M. G. (2013). }\end{array}$ & $\begin{array}{l}\text { Identificando o potencial de } \\
\text { inovação das organizações por } \\
\text { meio da análise do portfólio de } \\
\text { projetos de tecnologia da } \\
\text { informação }\end{array}$ & Gestão \& Produção & 6 \\
\hline 7 & $\begin{array}{c}\text { ALVES M. E., \& VARELA, C. A. } \\
\text { (2013). }\end{array}$ & $\begin{array}{l}\mathrm{R}, \mathrm{D} \& \mathrm{I} \text { in Electric Sector: a } \\
\text { management model }\end{array}$ & $\begin{array}{l}\text { Journal of Technology } \\
\text { Management \& Innovation }\end{array}$ & 2 \\
\hline 8 & JERBRANT, ANNA. (2014). & $\begin{array}{l}\text { A maturation model for } \\
\text { project-based organisations - } \\
\text { with uncertainty management } \\
\text { as an ever-present multi- } \\
\text { project management focus }\end{array}$ & $\begin{array}{l}\text { South African Journal of } \\
\text { Economic and } \\
\text { Management Sciences }\end{array}$ & 6 \\
\hline 9 & $\begin{array}{l}\text { MARZAGÃO, D. S. L., \& } \\
\text { CARVALHO, M. M. (2014). }\end{array}$ & $\begin{array}{l}\text { Disfunções na implementação } \\
\text { da gestão de portfólio de } \\
\text { projetos: um estudo } \\
\text { quantitativo }\end{array}$ & Production & 3 \\
\hline 10 & $\begin{array}{c}\text { LARIEIRA, C. L. C., \& ALBERTIN, A. } \\
\text { L. (2015). }\end{array}$ & $\begin{array}{l}\text { Um estudo sobre os fatores } \\
\text { organizacionais que } \\
\text { influenciam a gestão de } \\
\text { portfólio de projetos de } \\
\text { tecnologia da informação e } \\
\text { comunicação }\end{array}$ & $\begin{array}{l}\text { Revista Eletrônica de } \\
\text { Administração }\end{array}$ & 4 \\
\hline 11 & $\begin{array}{l}\text { JUGEND, D., \& FIGUEIREDO, J. } \\
\text { (2017). }\end{array}$ & $\begin{array}{l}\text { Integrando sustentabilidade } \\
\text { ambiental e gestão de portfólio } \\
\text { de projetos: estudo de caso em } \\
\text { uma empresa de energia }\end{array}$ & Gestão \& Produção & 0 \\
\hline
\end{tabular}

Fonte: Os autores, 2018 
O resultado indica a preocupação das organizações em gerenciar seu portfólio de projetos de modo a atender aos objetivos estratégicos organizacionais, além disso, o gerenciamento de portfólio exige um método de avaliação de projetos que os monitore durante todos os seus ciclos de vida de forma a garantir a entrega dos resultados.

A intervenção iniciou em outubro de 2018 e finalizou com a devolutiva para o Ceasb em dezembro de 2018. Com base na experiência da pesquisadora e após a revisão bibliográfica e revisão sistemática, foi iniciado então a proposta de estruturação do processo de gerenciamento de portfólio de projetos para o Ceasb.

\section{Resultados obtidos e análise}

Convém apresentar primeiramente as características da instituição em estudo e contextualizar a situação-problema antes de descrever os resultados obtidos.

\subsection{Caraterização da Instituição}

A intervenção foi realizada no Centro de Estudos Avançados em Segurança de Barragens, Ceasb. Este Centro é resultado de uma parceria entre a Itaipu Binacional e a Fundação Parque Tecnológico Itaipu tendo como foco principal o desenvolvimento de projetos de pesquisas aplicadas à Usina de Itaipu.

O Centro possui uma plataforma tecnológica que permite o desenvolvimento de soluções de pesquisa aplicada onde participam pesquisadores e bolsistas das universidades, funcionários da Itaipu, além de pesquisadores com dedicação exclusiva. O Portfólio de projetos é formado por oito áreas de concentração, das quais podemos destacar: Modelagem tridimensional, Monitoramento da Saúde Estrutural; Instrumentação de Barragens; Geotecnia; Concreto; Monitoramento e Análise de Risco; Cadastro de Barragens; e, Aplicações e desenvolvimento de tecnologias inovadoras em Usinas Hidrelétricas. Para desenvolver os projetos o Ceasb fomenta por meio de um projeto de pesquisa: bolsas aos alunos de graduação, pós-graduação, mestrado e doutorado, além do recurso necessário para o desenvolvimento destas pesquisas, com software, hardware, equipamentos, insumos, livros, e apoio na participação de eventos para publicação do resultado dos estudos. Essas oportunidades constituem um espaço de incentivo a pesquisa, possibilitando a qualificação de profissionais e formação de uma comunidade de pesquisa científica na região. 


\subsection{Descrição da situação-problema}

O orçamento para execução dos projetos de pesquisa do Ceasb é proveniente da Itaipu Binacional, por meio de convênio com a Fundação Parque Tecnológico Itaipu. Como são recebidas várias propostas de projetos o Ceasb não dispõe de um processo padronizado de gerenciamento de portfólio. Sem uma avaliação criteriosa podemos executar projetos que não estejam relacionados as estratégias organizacionais e que apresentem resultados insatisfatórios.

\subsection{Resultados}

O propósito deste relato técnico foi apresentar a estruturação do processo de gerenciamento de portfólio de projetos do Centro de Estudos Avançados em Segurança de Barragens.

\subsubsection{Revisão Bibliográfica}

O gerenciamento do portfólio de projetos (PPM) tem se mostrado um tema de destaque desde os anos 90, assim como o portfólio de negócio nos anos 70 e 80. No entanto, ainda há pouca evidência da prática estruturada de gestão de portfólio nas organizações (JEFFERY; LELIVELD, 2004).

Com base nos levantamentos da literatura, três modelos, desenvolvidos na década de 90 por WHEELWRIGHT E CLARK (1992), COOPER, EDGETT E KLEINSCHMIDT (1997) e ARCHER E GHASEMZADEH (1999), destacam-se como referência na área de PPM.

Outros dois modelos apresentados na literatura são mais recentes - um deles é o guia de gerenciamento de portfólio do PMI (2013). O outro modelo selecionado foi desenvolvido por Rabechini Jr., Maximiano e Martins (2005) que tem como base os três primeiros modelos e foi aplicado em uma empresa brasileira prestadora de serviços de interconexão eletrônica.

Para a análise comparativa dos cinco modelos de PPM foram considerados sete estágios: alinhamento com prioridades estratégicas, definição dos recursos, classificação dos projetos, avaliação individual, seleção e priorização dos projetos, alocação dos recursos e controle do portfólio. 


\section{Quadro 1}

\section{Análise comparativa dos modelos de PPM}

\begin{tabular}{|c|c|c|c|c|}
\hline \multicolumn{5}{|c|}{ ALINHAMENTO ESTRATÉGICO } \\
\hline $\begin{array}{l}\text { Wheelwright e Clark } \\
\text { (1992) }\end{array}$ & $\begin{array}{c}\text { Cooper, Edgette } \\
\text { Kleinschmidt (1997b) }\end{array}$ & $\begin{array}{c}\text { Archere } \\
\text { Ghasemzadeh } \\
\text { (1999) }\end{array}$ & $\begin{array}{l}\text { Rabechini Jr., } \\
\text { Maximiano e } \\
\text { Martins (2005) }\end{array}$ & PMI (2013) \\
\hline $\begin{array}{l}\text { Não abordam o } \\
\text { processo de definição } \\
\text { e análise dos critérios, } \\
\text { mas defendem que os } \\
\text { projetos devem } \\
\text { possuir alinhamento } \\
\text { com a estratégia da } \\
\text { organização. }\end{array}$ & $\begin{array}{l}\text { Os processos indicam } \\
\text { a importância de se } \\
\text { ter critérios claros, } \\
\text { alinhados à estratégia } \\
\text { organizacional. }\end{array}$ & $\begin{array}{l}\text { Ressaltam que a } \\
\text { determinação do } \\
\text { foco estratégico do } \\
\text { portfólio deve ser } \\
\text { conduzida em altos } \\
\text { níveis gerenciais e } \\
\text { não no comitê de } \\
\text { gestão do portfólio } \\
\text { de projetos, } \\
\text { porque envolve a } \\
\text { própria direção } \\
\text { estratégica da } \\
\text { organização, } \\
\text { mesmo sendo } \\
\text { crítico o } \\
\text { alinhamento do } \\
\text { portfólio com os } \\
\text { objetivos de } \\
\text { negócio. }\end{array}$ & $\begin{array}{l}\text { O processo } \\
\text { Preparação do } \\
\text { processo de } \\
\text { implementação do } \\
\text { portfólio aborda as } \\
\text { atividades } \\
\text { consideradas no } \\
\text { processo de } \\
\text { definição de } \\
\text { critérios. }\end{array}$ & $\begin{array}{l}\text { Pressupõe que a } \\
\text { organização tenha } \\
\text { um processo } \\
\text { estratégico definido, } \\
\text { com metas e } \\
\text { objetivos bem } \\
\text { definidos, e que as } \\
\text { decisões de } \\
\text { avaliação, } \\
\text { classificação, } \\
\text { seleção e } \\
\text { priorização sejam } \\
\text { tomadas com base } \\
\text { neste plano, não } \\
\text { sendo } \\
\text { explicitamente } \\
\text { abordado um } \\
\text { processo para } \\
\text { definição dos } \\
\text { critérios. }\end{array}$ \\
\hline \multicolumn{5}{|c|}{ CLASSIFICAÇÃO DE PROJETOS } \\
\hline $\begin{array}{l}\text { Wheelwright e Clark } \\
\text { (1992) }\end{array}$ & $\begin{array}{c}\text { Cooper, Edgett e } \\
\text { Kleinschmidt (1997b) }\end{array}$ & $\begin{array}{c}\text { Archere } \\
\text { Ghasemzadeh } \\
\text { (1999) }\end{array}$ & $\begin{array}{l}\text { Rabechini Jr., } \\
\text { Maximiano e } \\
\text { Martins (2005) }\end{array}$ & PMI (2013) \\
\hline $\begin{array}{l}\text { Os tipos de projetos } \\
\text { propostos pelos } \\
\text { autores são definidos } \\
\text { com base em uma } \\
\text { matriz de impacto dos } \\
\text { projetos em produtos } \\
\text { e processos. }\end{array}$ & $\begin{array}{l}\text { Este método não } \\
\text { aborda no modelo a } \\
\text { classificação de } \\
\text { projetos, pois dá } \\
\text { ênfase aos projetos } \\
\text { de desenvolvimento } \\
\text { de novos produtos. }\end{array}$ & $\begin{array}{l}\text { O modelo não } \\
\text { aborda } \\
\text { explicitamente a } \\
\text { classificação ou } \\
\text { categorização de } \\
\text { projetos, apesar de } \\
\text { considerá-la nos } \\
\text { três processos de } \\
\text { avaliação. }\end{array}$ & $\begin{array}{l}\text { Este modelo não } \\
\text { contempla a } \\
\text { classificação e ou } \\
\text { categorização de } \\
\text { projetos. }\end{array}$ & $\begin{array}{l}\text { No processo de } \\
\text { categorização as } \\
\text { categorias devem } \\
\text { ser definidas com } \\
\text { base no plano } \\
\text { estratégico e os } \\
\text { projetos devem ser } \\
\text { atribuídos a uma } \\
\text { categoria específica. }\end{array}$ \\
\hline \multicolumn{5}{|c|}{ AVALIAÇÃO DE PROJETOS } \\
\hline $\begin{array}{l}\text { Wheelwright e Clark } \\
\text { (1992) }\end{array}$ & $\begin{array}{c}\text { Cooper, Edgette } \\
\text { Kleinschmidt (1997b) }\end{array}$ & $\begin{array}{c}\text { Archere } \\
\text { Ghasemzadeh } \\
\text { (1999) }\end{array}$ & $\begin{array}{l}\text { Rabechini Jr., } \\
\text { Maximiano e } \\
\text { Martins (2005) }\end{array}$ & PMI (2013) \\
\hline $\begin{array}{l}\text { A etapa sete deste } \\
\text { processo, em } \\
\text { conjunto com o funil } \\
\text { de desenvolvimento } \\
\text { prevê a escolha dos } \\
\text { projetos que serão } \\
\text { iniciados ou } \\
\text { continuados e, para } \\
\text { isso, pressupõe-se que }\end{array}$ & $\begin{array}{l}\text { Os processos } \\
\text { Imperativos } \\
\text { estratégicos' na } \\
\text { revisão do portfólio e } \\
\text { Modelo de pontuação } \\
\text { no Stage Gate } \\
\text { indicam a importância } \\
\text { de se avaliar os } \\
\text { projetos com base }\end{array}$ & $\begin{array}{l}\text { Os processos Pré- } \\
\text { avaliação, onde é } \\
\text { verificada a } \\
\text { aderência dos } \\
\text { projetos à } \\
\text { estratégia; Análise } \\
\text { individual de } \\
\text { projetos, onde é } \\
\text { realizada a análise }\end{array}$ & $\begin{array}{l}\text { Apesar dos } \\
\text { autores } \\
\text { apresentarem um } \\
\text { processo } \\
\text { denominado } \\
\text { avaliação, este } \\
\text { processo não se } \\
\text { aprofunda nas } \\
\text { técnicas de }\end{array}$ & $\begin{array}{l}\text { Este modelo } \\
\text { considera as } \\
\text { análises quantitativa } \\
\text { e qualitativa, sendo } \\
\text { proposto o uso de } \\
\text { modelos de } \\
\text { pontuação, } \\
\text { representação } \\
\text { gráfica e }\end{array}$ \\
\hline
\end{tabular}




\begin{tabular}{|c|c|c|c|c|}
\hline $\begin{array}{l}\text { eles sejam avaliados. } \\
\text { No entanto, os } \\
\text { autores não se } \\
\text { aprofundam nas } \\
\text { técnicas de avaliação } \\
\text { e no detalhamento do } \\
\text { processo de avaliação. }\end{array}$ & $\begin{array}{l}\text { nos critérios } \\
\text { estabelecidos, mas } \\
\text { não aprofundam nas } \\
\text { técnicas de avaliação } \\
\text { e no detalhamento do } \\
\text { processo de } \\
\text { avaliação. }\end{array}$ & $\begin{array}{l}\text { financeira e de } \\
\text { risco dos projetos } \\
\text { novos e dos } \\
\text { projetos; e } \\
\text { Avaliação, que } \\
\text { complementa o } \\
\text { processo anterior, } \\
\text { são adotados para } \\
\text { avaliação dos } \\
\text { projetos. }\end{array}$ & $\begin{array}{l}\text { avaliação e no } \\
\text { detalhamento do } \\
\text { processo de } \\
\text { avaliação. Apenas } \\
\text { estabelece uma } \\
\text { lista priorizada de } \\
\text { projetos. }\end{array}$ & $\begin{array}{l}\text { recomendações } \\
\text { para os "tomadores } \\
\text { de decisão". }\end{array}$ \\
\hline \multicolumn{5}{|c|}{ SELEÇÃO E PRIORIZAÇÃO DE PROJETOS } \\
\hline $\begin{array}{c}\text { Wheelwright e Clark } \\
\text { (1992) }\end{array}$ & $\begin{array}{c}\text { Cooper, Edgett e } \\
\text { Kleinschmidt (1997b) }\end{array}$ & $\begin{array}{c}\text { Archere } \\
\text { Ghasemzadeh } \\
\text { (1999) }\end{array}$ & $\begin{array}{l}\text { Rabechini Jr., } \\
\text { Maximiano e } \\
\text { Martins (2005) }\end{array}$ & PMI (2013) \\
\hline $\begin{array}{l}\text { Os projetos devem ser } \\
\text { selecionados na etapa } \\
\text { sete deste processo e } \\
\text { no portão B do funil } \\
\text { de desenvolvimento. } \\
\text { No entanto, os } \\
\text { autores não se } \\
\text { aprofundam nas } \\
\text { técnicas e no } \\
\text { detalhamento dos } \\
\text { processos de seleção } \\
\text { e priorização de } \\
\text { projetos. }\end{array}$ & $\begin{array}{l}\text { Os processos checar a } \\
\text { prioridade dos } \\
\text { projetos e Checar o } \\
\text { alinhamento e } \\
\text { balanceamento } \\
\text { estratégico, ambos na } \\
\text { revisão do portfólio, } \\
\text { determinam os } \\
\text { projetos que devem } \\
\text { ser mantidos ou } \\
\text { excluídos, bem como } \\
\text { a prioridade no } \\
\text { desenvolvimento. }\end{array}$ & $\begin{array}{l}\text { A seleção do } \\
\text { portfólio envolve a } \\
\text { comparação } \\
\text { simultânea de um } \\
\text { número de } \\
\text { projetos em uma } \\
\text { dimensão } \\
\text { específica para } \\
\text { obter a sequência } \\
\text { desejada dos } \\
\text { projetos. }\end{array}$ & $\begin{array}{l}\text { O processo } \\
\text { proposto pelos } \\
\text { autores tem como } \\
\text { objetivo produzir } \\
\text { uma lista de } \\
\text { projetos } \\
\text { prioritários, mas } \\
\text { eles não se } \\
\text { aprofundam nas } \\
\text { técnicas e no } \\
\text { detalhamento dos } \\
\text { processos de } \\
\text { seleção e } \\
\text { priorização de } \\
\text { projetos. }\end{array}$ & $\begin{array}{l}\text { Seleção dos } \\
\text { projetos por } \\
\text { critérios } \\
\text { estratégicos. } \\
\text { Priorização pelo } \\
\text { ranqueamento em } \\
\text { cada categoria e } \\
\text { posterior } \\
\text { ranqueamento } \\
\text { geral, apoiando-se } \\
\text { no resultado do } \\
\text { modelo de } \\
\text { pontuação e da } \\
\text { determinação pelos } \\
\text { "tomadores de } \\
\text { decisão" dos } \\
\text { projetos prioritários. }\end{array}$ \\
\hline \multicolumn{5}{|c|}{ CONTROLE E MONITORAMENTO } \\
\hline $\begin{array}{c}\text { Wheelwright e Clark } \\
\text { (1992) }\end{array}$ & $\begin{array}{c}\text { Cooper, Edgette } \\
\text { Kleinschmidt (1997b) }\end{array}$ & $\begin{array}{c}\text { Archere } \\
\text { Ghasemzadeh } \\
\text { (1999) }\end{array}$ & $\begin{array}{l}\text { Rabechini Jr., } \\
\text { Maximiano e } \\
\text { Martins (2005) }\end{array}$ & PMI (2013) \\
\hline $\begin{array}{l}\text { Apresentam na oitava } \\
\text { fase a necessidade de } \\
\text { buscar oportunidades } \\
\text { de melhoria e integrá- } \\
\text { las ao plano agregado } \\
\text { de projetos, mas não } \\
\text { se aprofundam nas } \\
\text { técnicas de } \\
\text { mensuração e } \\
\text { avaliação de } \\
\text { desempenho dos } \\
\text { projetos em avaliação } \\
\text { e/ou andamento. }\end{array}$ & $\begin{array}{l}\text { É necessário ajustar o } \\
\text { esquema de portões, } \\
\text { a partir da avaliação } \\
\text { de projetos, na } \\
\text { revisão do portfólio. } \\
\text { Mas não detalham o } \\
\text { processo. }\end{array}$ & $\begin{array}{l}\text { O ajuste do } \\
\text { portfólio identifica } \\
\text { desvios no } \\
\text { planejamento e } \\
\text { execução dos } \\
\text { projetos e propõe } \\
\text { revisões do } \\
\text { portfólio para } \\
\text { acomodar estes } \\
\text { desvios. }\end{array}$ & $\begin{array}{l}\text { O processo revisão } \\
\text { e controle de } \\
\text { projetos busca } \\
\text { identificar desvios } \\
\text { nos projetos em } \\
\text { execução e propor } \\
\text { revisões no } \\
\text { portfólio para } \\
\text { acomodar estes } \\
\text { desvios. }\end{array}$ & $\begin{array}{l}\text { Avaliação periódica } \\
\text { em gates, } \\
\text { verificando os } \\
\text { indicadores de } \\
\text { performance e } \\
\text { verificação do } \\
\text { alinhamento do } \\
\text { portfólio com a } \\
\text { estratégia da } \\
\text { organização. }\end{array}$ \\
\hline
\end{tabular}

Fonte: Adaptado de Castro e Carvalho (2010).

\section{Os modelos de gestão de portfólio descritos por Wheelwright e Clark (1992) Cooper, Edgett e}

Kleinschmidt (1997), Archer e Ghasemzadeh (1999), Rabechini Jr et al. (2005) e PMI (2013) convergem 
em cinco processos chaves - alinhamento estratégico; classificação ou categorização de projetos; avaliação dos projetos; seleção e priorização de projetos; monitoramento e controle.

De acordo com Wheelwright e Clark (1992), a estruturação de um portfólio de projetos é reflexo da categorização quanto ao nível de modificação em produto e processo que o projeto demanda. Esta categorização disponibiliza aos gestores uma visão dos recursos que os projetos demandam para a sua implementação e a sua contribuição.

O modelo de Cooper, Edgett e Kleinschmidt (1997), menciona que é necessário integrar, de forma harmônica, as decisões de portões (gates) e de portfólio para minimizar os conflitos entre as decisões dos portões e as revisões de portfólio.

Segundo Archer e Ghasemzadeh (1999) seu modelo objetiva a simplificação do processo de seleção de projetos a partir da segmentação do processo em fases e estágios, desde as considerações relativas à estratégia inicial - modo mais amplo - até a elaboração final do portfólio.

Optou-se por utilizar como base o modelo do PMI (2013), pois destina-se a todos os tipos de organização. O modelo do PMI é observado na figura 02.

Figura 2

Processos da gestão de portfólio

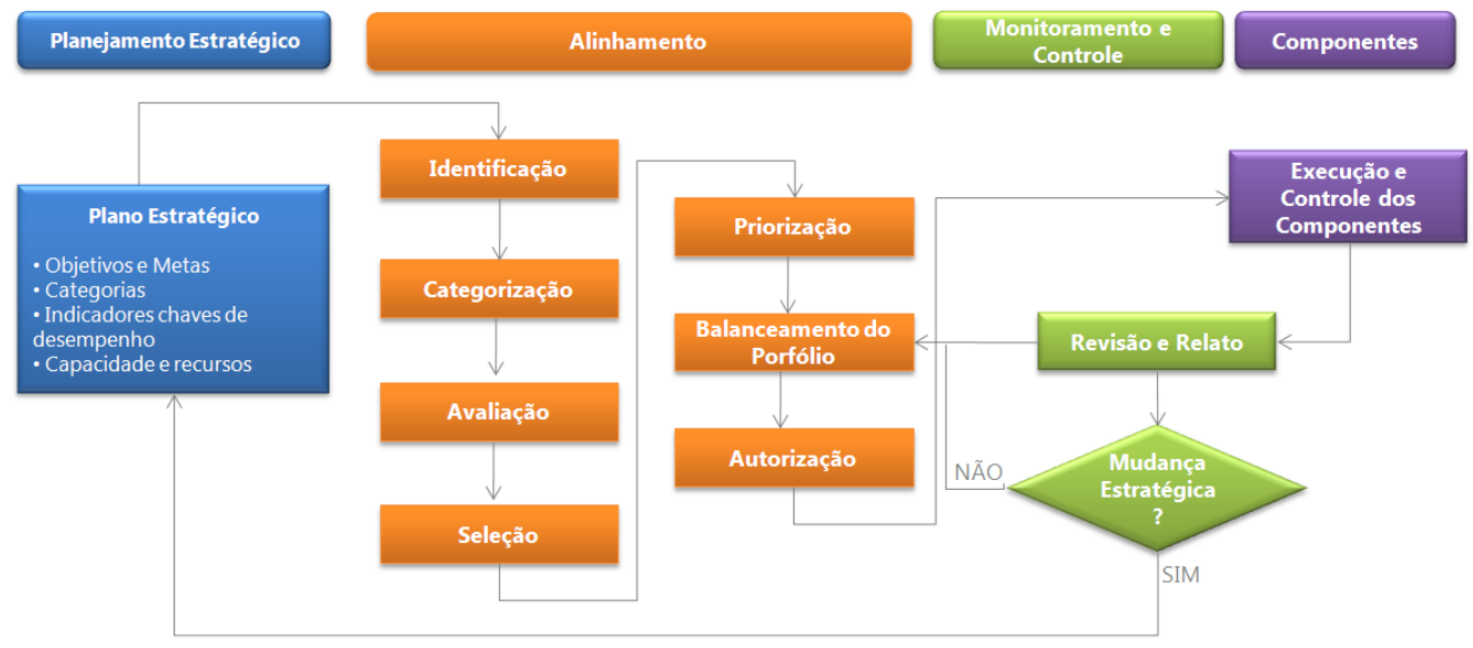

Fonte: (PMI, 2006)

Por meio dos processos é possível visualizar a integração do planejamento estratégico com o gerenciamento de portfólio. De acordo com Vargas (2010), não existe um modelo ideal que abranja os critérios corretos a serem utilizados por qualquer tipo de organização na priorização e seleção de projetos. Quem determina esses critérios é o planejador ou o tomador de decisão, com base nas suas preferências e valores. Neste sentido, foram implementadas ferramentas e estratégias para a 
estruturação dos processos de gerenciamento de portfólio do de maneira a atender as necessidades do Ceasb.

\subsubsection{Estruturação do Processo de Gerenciamento de Portfólio do Ceasb}

Com base no referencial teórico apresentado e na metodologia, apresentamos a proposta de estruturação de processos de gerenciamento de portfólio do Ceasb, ilustrada na figura 02.

No Processo de Alinhamento do Gerenciamento do Portfólio os projetos são identificados, categorizados, avaliados, selecionados, priorizados e aprovados considerando o seu alinhamento às estratégias da Fundação Parque Tecnológico Itaipu e Centro de Estudos Avançados em Segurança de Barragens - Ceasb, além dos limites orçamentários e os resultados esperados. O Planejamento Estratégico da FPTI permeia todas as etapas do processo.

Os projetos de pesquisa aplicada devem prezar pela qualificação técnica-científica, visando à transformação do resultado da pesquisa em inovação tecnológica, desenvolvendo atividades de natureza criativa ou empreendedora, de forma sistemática, com vista à geração de novos conhecimentos ou aplicação inovadora de conhecimentos existentes, inclusive para investigação de novas aplicações.

O processo estruturado foi inspirado no conjunto de processos sugeridos pelo PMI (2013), além disso, para a composição dos critérios e indicadores a serem utilizados nesta proposta, buscou-se orientação no Manual de P\&D da ANEEL (2012), além da vivência da pesquisadora durante todos os anos de atuação no Ceasb. 


\section{Figura 3}

Processo de gerenciamento do portfólio do Ceasb

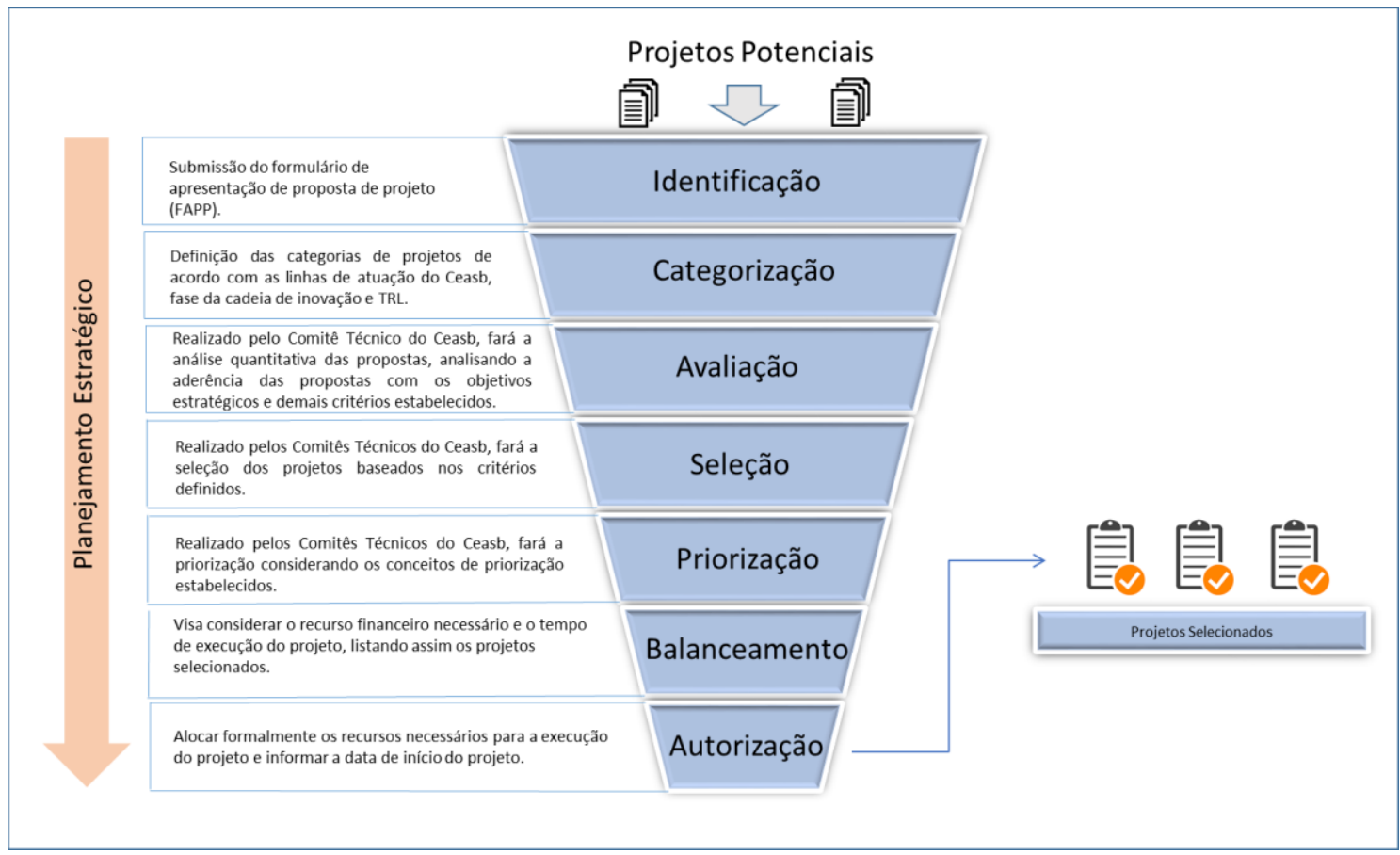

Fonte: Os autores, 2019.

\subsubsection{Processo de identificação}

Os proponentes de projetos (pesquisadores) deverão preencher o Formulário de Proposta de Projeto (FAPP), que contempla objetivo do projeto, justificativa, resultados esperados, cronograma e custos. Caso seja identificado que o Formulário do Projeto está incompleto, o Ceasb deverá entrar em contato solicitando-o novamente, possibilitando sua avaliação. Propostas identificadas como demandas ou outros trabalhos que não possuam características de projetos, deverão ser canceladas.

A qualidade, consistência e clareza das informações contidas no FAPP auxiliarão o processo de avaliação e seleção. É importante buscar informações do projeto no maior nível de detalhamento possível, objetivando facilitar a tomada de decisões.

\subsubsection{Categorização dos projetos}

Após identificação, esta fase tem como objetivo agrupar projetos do portfólio nas linhas de pesquisas do Ceasb e considerados relevantes estrategicamente, permitindo a análise, seleção, priorização e aprovação dos projetos. Com base nas linhas de pesquisa do Ceasb, os projetos serão agrupados em: 
Figura 4

Linhas de pesquisa do Ceasb

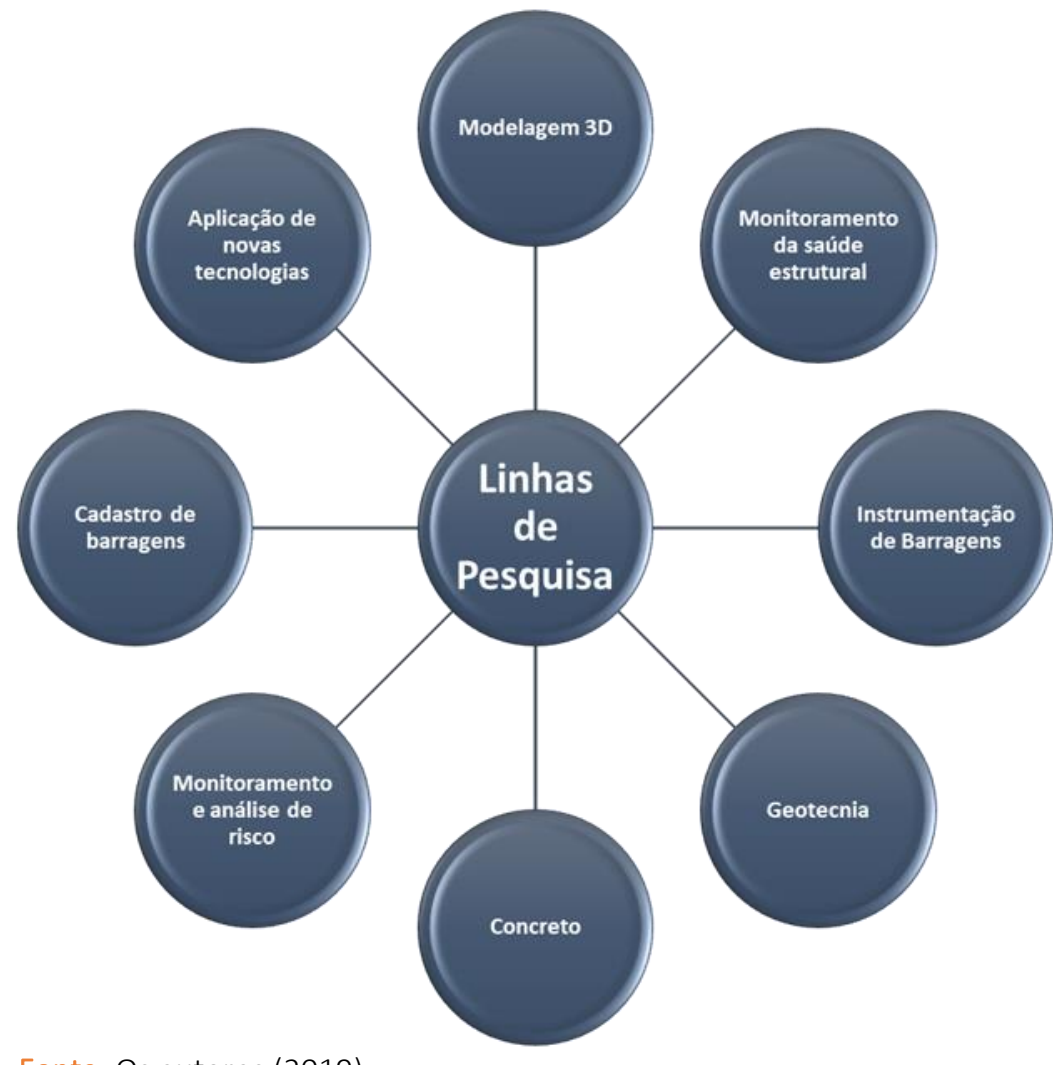

Fonte: Os autores (2019).

Cada proposta de projeto deverá estar associada a apenas uma categoria, de forma a facilitar o processo de avaliação e seleção. Caso uma proposta atenda a mais de uma categoria, deverá ser associada a aquela que mais se enquadrar. Faz-se necessária a categorização pois para cada linha de pesquisa tem-se um Comitê Técnico para análise.

\subsubsection{Avaliação dos projetos}

Para a avaliação foi escolhido o método de pontuação ou scoring que consiste, basicamente, na definição de certos critérios preestabelecidos, com intuito de selecionar e priorizar o projeto que na somatória obter melhor desempenho. Segundo Sbragia e Sbragia (1999), devido às diferenças de importância dos critérios, são atribuídos pesos para caracterizar a diferença. Esses pesos são multiplicados pelas notas dadas pelo Comitê Técnico, para a definição da nota final de cada projeto. De acordo com a necessidade do Centro de Estudos Avançados em Segurança de barragens foram criados três tipos de critérios: técnicos, de resultados e administrativos. O critério, a descrição e o peso estão listados no quadro 1. 
Tabela 2

Critérios de avaliação

\begin{tabular}{|c|c|c|c|}
\hline TIPO & CRITÉRIO & DESCRIÇÃO & PESO \\
\hline \multirow{5}{*}{ Técnicos } & Originalidade & $\begin{array}{c}\text { Deverá considerar o problema a ser solucionado e a ausência da } \\
\text { solução/pesquisa disponível no mercado. Analisa-se o estado-da- } \\
\text { arte, os desafios e os avanços propostos, em termos científicos } \\
\text { e/ou tecnológicos, considerando-se o produto/serviço principal } \\
\text { do projeto. }\end{array}$ & 11 \\
\hline & $\begin{array}{l}\text { Busca de } \\
\text { anterioridade }\end{array}$ & $\begin{array}{l}\text { Deverá ser apresentada a busca de anterioridade, referente ao } \\
\text { objeto a ser desenvolvido. Este, deverá embasar a originalidade } \\
\text { do projeto. Espera-se que sejam apresentados os trabalhos que } \\
\text { tenham algum tipo de similaridade e a diferença destes trabalhos } \\
\text { com a proposta atual. }\end{array}$ & 5 \\
\hline & Aplicabilidade & $\begin{array}{l}\text { O resultado deverá ser avaliado com base no âmbito e no } \\
\text { potencial de aplicação. }\end{array}$ & 6 \\
\hline & $\begin{array}{l}\text { Relevância } \\
\text { científica }\end{array}$ & $\begin{array}{c}\text { Deverão avaliar as contribuições ou impactos do projeto em } \\
\text { termos científicos. }\end{array}$ & 4 \\
\hline & $\begin{array}{l}\text { Qualificação do } \\
\text { Coordenador }\end{array}$ & $\begin{array}{c}\text { Deverá ser considerada a qualificação do coordenador. Por meio } \\
\text { do currículo lates, deverão ser considerados as publicações, } \\
\text { participação em projetos de pesquisa, orientações, participação } \\
\text { em congressos e afins, assim como as patentes e trabalhos } \\
\text { desenvolvidos relacionados ao projeto. }\end{array}$ & 12 \\
\hline \multirow[b]{2}{*}{ Resultados } & $\begin{array}{l}\text { Desenvolvimento } \\
\text { de soluções } \\
\text { inovadoras para } \\
\text { Itaipu Binacional }\end{array}$ & $\begin{array}{l}\text { Oferecer soluções inovadoras voltadas para } \\
\text { produtos/serviços/processos, capaz de gerar impacto significativo } \\
\text { para a Itaipu Binacional e outras empresas do setor. }\end{array}$ & 15 \\
\hline & $\begin{array}{l}\text { Potencial de } \\
\text { geração de } \\
\text { serviços e } \\
\text { produtos } \\
\text { especializados }\end{array}$ & $\begin{array}{l}\text { Oferecer sustentabilidade financeira e/ou econômica, } \\
\text { possibilitando a inserção de produtos e serviços com potencial de } \\
\text { mercado, visando negócios com alta possibilidade de expansão. }\end{array}$ & 15 \\
\hline \multirow{3}{*}{ Administrativos } & $\begin{array}{l}\text { Razoabilidade de } \\
\text { custos }\end{array}$ & $\begin{array}{l}\text { Deverá ser avaliada mediante a análise dos impactos econômicos } \\
\text { decorrentes da aplicação dos resultados do projeto, confrontando } \\
\text { os investimentos com os benefícios. }\end{array}$ & 10 \\
\hline & $\begin{array}{l}\text { Alinhamento } \\
\text { Estratégico da } \\
\text { FPTI }\end{array}$ & Deverá estar alinhado ao Planejamento Estratégico da FPTI. & 12 \\
\hline & Risco do Projeto & $\begin{array}{l}\text { Deverá considerar o risco gerado pelo projeto, os quais impactam } \\
\text { na sua execução. }\end{array}$ & 10 \\
\hline
\end{tabular}

Fonte: Os autores (2019).

\subsubsection{Processo de seleção projetos}

Após a avaliação é obtida a pontuação final de cada projeto, gerando assim, uma lista dos projetos potencias aprovados.

A classificação (ranking) do projeto será obtida com base na média aritmética ponderada das notas obtidas nas avaliações, compondo assim a lista de projetos selecionados. 


\subsubsection{Processo de priorização}

Após a avaliação e seleção dos projetos, passa-se para a fase de priorização. Essa priorização deverá ser feita considerando o alinhamento estratégico, os recursos financeiros necessários a execução e o resultado que se espera com este projeto. Sendo assim é gerado um ranking geral com a relação de todos os projetos aprovados.

\subsubsection{Processo de Balanceamento}

Após priorização dos projetos, passa-se para a fase de balanceamento. Esse deverá considerar o recurso financeiro necessário e o tempo de execução do projeto. Sendo assim, considerando o ranking da priorização teremos os projetos autorizados para execução imediata, com conceito "excelente" e "muito bom", os projetos com conceito "bom" aguardarão a comunicação para início da execução e os conceitos "regular", "ruim" e "inadequado" serão reprovados.

\subsubsection{Processo de autorização}

O proponente da proposta aprovada, participará de uma reunião de alinhamento com o Comitê Técnico e Gestor do Ceasb, que resultará no alinhamento do projeto a ser desenvolvido no Ceasb. Nesta ocasião, o projeto será oficialmente autorizado sendo alocado formalmente os recursos necessários para sua execução.

\subsubsection{Execução dos projetos}

Os projetos autorizados deverão seguir a Metodologia de Gerenciamento de Projetos da Fundação Parque Tecnológico Itaipu - FPTI. Caberá ao gerente do projeto, analista do projeto e proponente em reunião detalhar as atividades, definir os prazos e responsáveis. Nesta ocasião, o projeto de pesquisa é inserido no Software de gerenciamento, Basi. Além disso, será estruturada a "página" no Software Confluence, no qual será registrada a gestão do conhecimento contemplando do período de execução até a entrega dos resultados.

\subsubsection{Processo de monitoramento e controle}

Monitorar e Controlar o portfólio de projetos significa acompanhar o andamento dos projetos de pesquisa, bem como verificar se as estratégias estabelecidas estão de fato sendo implementadas. Para isso, são realizadas reuniões trimestrais, na qual o proponente do projeto deve apresentar as atividades executadas, para o Comitê Técnico da Itaipu e Comitê Gestor do Ceasb. Neste momento, 
devido a necessidade, o escopo pode ser alterado, projeto pode ser suspenso e/ou cancelado, ou a pesquisa segue normalmente conforme o planejado até a data de encerramento.

\section{Considerações finais}

Este estudo buscou contribuir tanto para a organização objeto do estudo quanto à comunidade acadêmica científica, resultando na estruturação do processo de gestão de portfólio de projetos, uma proposta no Centro de Estudos Avançados em Segurança de Barragens (Ceasb), evidenciada como aplicação do método científico da pesquisa-ação.

Entende-se que este estudo atendeu aos objetivos propostos, ofertando uma contribuição inicial para a construção de conhecimentos no tema de gerenciamento de portfólio de projetos. Além disso, foi possível identificar que a gestão de portfólio de projetos consiste em um conjunto de processo do gerenciamento de projetos que proporciona a interligação dos objetivos estratégicos com a gestão dos programas e projetos, tendo a finalidade de possibilitar análise, recomendação, autorização, agilidade e monitoramento dos projetos. Por meio dela consegue-se selecionar os melhores projetos e controlá-los para que continuem satisfazendo os propósitos da instituição, mesmo depois do início do desenvolvimento. Esse processo tem surgido como uma abordagem de apoio a tomada de decisão nas organizações. Seus métodos, técnicas e ferramentas contribuem para a minimização das incertezas e sistematização da decisão. Assim, o gerenciamento de portfólio garante que o conjunto de projetos seja direcionado para atender aos objetivos estratégicos. Quando realizado com sucesso, alguns dos benefícios que podem ser alcançados são: colocação de produtos/serviços no mercado de maneira mais rápida, aumento significativo no número de projetos concluídos com os mesmos recursos, redução da duração dos projetos e aumento no índice de sucesso e margem de lucro.

É importante salientar que o gerenciamento de portfólio exige um método de avaliação de projetos que os monitore durante todos os seus ciclos de vida de forma a garantir a entrega dos resultados. Com o objetivo de maximizar a contribuição dos resultados, a gestão do portfólio vai proporcionar aos tomadores de decisão, a partir da aplicação de conhecimentos e técnicas, condições para a escolha e gestão de projetos alinhados à estratégia da organização.

Acredita-se que com a estruturação das etapas do processo de alinhamento do gerenciamento de portfólio de projetos de P\&D, bem como os modelos de formulários e critérios definidos, possam contribuir para a maximização da imparcialidade na seleção e alinhamento aos objetivos estratégicos da organização. O resultado deste trabalho poderá subsidiar o Ceasb a visualizar e entender de forma clara e simples seu processo de portfólio. Também será possível identificar que o portfólio se relaciona ao cumprimento dos processos de forma eficiente, de modo que é possível alcançar os objetivos estratégicos fazendo bom uso dos recursos disponíveis. Além disso, com a aplicação da proposta da 
gestão de portfólio de projetos de P\&D pode proporcionar a redução de riscos e o aumento dos temas pesquisados e projetos executados, criando assim, oportunidades para gerar inovações.

A contribuição deste estudo é limitada, pois a proposta foi somente para o Ceasb. Ademais, seria interessante testar o processo de gerenciamento de portfólio e propor as melhorias necessárias em outras empresas.

\section{Referências}

Archer, N. P., \& Ghasemzadeh, F. (1999a). An integrated framework for project portfolio selection. International Journal of Project Management, 17(4), 207-216.

Alves de Moraes, Edmilson, \& Varela, Carmen Augusta. (2013). R,D and I in Electric Sector: a Management Model. Journal of technology management \& innovation, 8(Supl. 1), 67. https://dx.doi.org/10.4067/S0718-27242013000300067

Barcaui, André B. PMO: Escritórios de Projetos, Programas e Portfólio na prática. Rio de Janeiro: Brasport, 2012.

Botelho, L. L. R., Cunha, C. C. A., \& Macedo, M. (2011). O método da revisão integrativa nos estudos organizacionais. Gestão e Sociedade, 5(11), 121-136.

Buys, A.J., \& Stander, M.J.. (2010). Linking projects to business strategy through project portfolio management. South African Journal of Industrial Engineering, 21(1), 59-68. Retrieved September 30, 2018, from http://www.scielo.org.za/scielo.php?script=sci_arttext\&pid=S2224$78902010000100006 \& \operatorname{lng}=e n \& \operatorname{lng}=e n$

Carvalho, M. M., Lopes, P. V. B. V. L., \& Marzagão, D. S. L. (2013). Gestão de portfólio de projetos: contribuições e tendências da literatura. Gestão \& Produção, 20(2), 433-453. http://dx.doi.org/10.1590/S0104-530X2013000200013

Carvalho, M. M.; Rabechini Jr, R. (2008) Construindo competências para gerenciar projetos: teoria e casos. São Paulo: Atlas.

Carvalho, M. M.; Rabechini Jr., R. Gestão de projetos na prática: casos Brasileiros. São Paulo: Editora Atlas, 2006.

Castro, Henrique Gonçalves de, \& Carvalho, Marly Monteiro de. (2010). Gerenciamento do portfolio de projetos: um estudo exploratório. Gestão \& Produção, 17(2), 283296. https://dx.doi.org/10.1590/S0104-530X2010000200006

Castro, Henrique Gonçalves de, \& Carvalho, Marly Monteiro de. (2010). Gerenciamento do portfólio de projetos (PPM): estudos de caso. Production, 20(3), 303-321. Epub July 09, 2010. https://dx.doi.org/10.1590/S0103-65132010005000044

Clark, K. \& Wheelwright, S.C. (1992) - Revolutionizing Product Development: quantum leaps in speed, efficiency, and quality. The Free Press. New York.

Cooper, R. G.; Edgett, S. J.; Kleinschmidt, E. J. New product portfolio management: practices and performance. Journal of Product Innovation Management, v. 16, n. 4, p. 333-351, 1999. 
Cooper, R. G.; Edgett, S. J.; Kleinschmidt, E. J. Portfolio management for new product development: result of an industry practices study. R\&D Management, v. 34, n. 4, p. 361-380, 2001b.

Dinsmore, P. C.; Cabanis-Brewin, J. (2009). AMA Manual de Gerenciamento de Projetos. (A. Cavalieri, J. L. Anselmo, F. Abdollahyan, \& M. F. Cota, Trads.). Rio de Janeiro: Brasport.

Fernandes, Aguinaldo Aragon; Abreu, Vladimir Ferraz. Implantando a governança de TI: da estratégia a gestão dos processos e serviços. 2. ed. Rio de Janeiro: Brasport, 2008.

Ghasemzadeh, F.; Archer, N., lyogun, P. A zero-one model for project portfolio selection and scheduling. Journal of the operational Research Society, v. 50, n. 7, p. 745-755, 1999. http://dx.doi.org/10.1057/palgrave.jors.2600767

Jaeger Neto, José Ignácio, Luciano, Edimara Mezzomo, \& Testa, Mauricio Gregianin. (2013). Identificando o potencial de inovação das organizações por meio da análise do portfólio de projetos de Tecnologia da Informação. Gestão \& Produção, 20(3), 495-510. https://dx.doi.org/10.1590/S0104-530X2013000300001

Jeffery, M., \& Lelived, I. (2014). Best practices in IT portfolio management. MIT Sloan Management Review, 41-49.

Jerbrant, Anna. (2014). A maturation model for project-based organisations - with uncertainty management as an ever-present multi-project management focus. South African Journal of Economic and Management Sciences, 17(1), 33-51.

Jugend, Daniel, \& Figueiredo, José. (2017). Integrando sustentabilidade ambiental e gestão de portfólio de projetos: estudo de caso em uma empresa de energia. Gestão \& Produção, 24(3), 526-537.

Kaiser, M. G.; Arbi, F. E.; Ahlemann, F. Successful Project Portfolio Management Beyond Project. International Journal of Management Project, Wiesbaden, v. 33, n. 1, p. 126- 139, January 2015. ISSN 0263-7863.

Larieira, Cláudio Luís Carvalho, \& Albertin, Alberto Luiz. (2015). Um estudo sobre os fatores organizacionais que influenciam a gestão de portfólio de projetos de tecnologia da informação e comunicação. REAd. Revista Eletrônica de Administração (Porto Alegre), 21(2), 515-547. https://dx.doi.org/10.1590/1413-2311.0462014.52299

Marzagão, Daniela Santana Lambert, \& Carvalho, Marly Monteiro de. (2014). Disfunções na implementação da gestão de portfólio de projetos: um estudo quantitativo. Production, 24(2), 337-350. Epub April 19, 2013. https://dx.doi.org/10.1590/\$0103-65132013005000018

Moraes, Renato de Oliveira, \& Laurindo, Fernando José Barbin. (2003). Um estudo de caso de gestão de portfolio de projetos de tecnologia da informação. Gestão \& Produção, 10(3), 311-328. https://dx.doi.org/10.1590/S0104-530X2003000300007

Nascimento, Paulo Tromboni de Souza. (2013). Portfolio generation goes beyond project selection: interdependencies must drive new alternatives creation. Gestão \& Produção, 20(1), 1322. https://dx.doi.org/10.1590/S0104-530X2013000100002 
Neely, A. The evolution of performance measurement research: developments in the last decade and a research agenda for the next. International Journal of Operations \& Production Management, v. 25, n. 12, p. 1264-1277, 2005.

http://dx.doi.org/10.1108/01443570510633648

PMI. (2006). The Standard for Portfolio Management (1a Edição).

PMI, 2008a, The Standard for Portfólio Management, Newtown Square, Project Management Institute - PMI.

Project Management Institute, PMI, (2013). The Standard of Portfolio Management. 3. ed. Project Management Institute, Inc. Newtown Square - PA.

Rabechini Jr, R., Maximiano, A. C. A., \& Martins, V. A. (2005). A adoção de gerenciamento de portfolio como uma alternativa gerencial: o caso de uma empresa prestadora de serviço de interconexão eletrônica. Production, 15(3), 416-433. https://dx.doi.org/10.1590/\$010365132005000300011

Rozenfeld, H.; Forcellini, F. A.; Amaral, D. C.; et al. Gestão de Desenvolvimento de Produto: uma referência para a melhoria do processo. 1 ed. São Paulo: Saraiva, 2006.

Thiollent, M. (1986). METODOLOGIA DA PESQUISA-AÇAO (2a). Cortez.

Vargas, R. V. (2010). Utilizando a programação multicritério (Analytic Hierarchy Process - AHP) para selecionar e priorizar projetos na gestão de portfólio. In PMI Global Congress 2010. Washington. 